\title{
Optimum Wire Busbar Design by Genetic Algorithm
}

\author{
Davor PETRANOVIĆ, Ante MARUŠIĆ, Juraj HAVELKA
}

\begin{abstract}
This work shows genetic algorithm approach to the optimum wire busbar design. Parameters of the wire busbar are mapped into a chromosome like a string. This includes insulator string type, wire conductor type and number, bundle wire conductor distance, rigid spacer number, phase distance, wire conductor nominal stress, 3D truss $L$ elements types and foundation type. GA uses natural selection on a population of such strings. The fitness function is the wire busbar price. GA performance is presented on one example with variation of input data - nominal current, short-circuit current and short-circuit duration.
\end{abstract}

Keywords: design; genetic algorithm; optimum; wire busbar

\section{INTRODUCTION}

The high voltage outdoor busbars are used for transfer of the electrical energy between connected feeder and transformer bays. Busbars and the necessary connection to the equipment can be of wire or tube conductors. Each of these busbar versions has certain advantages and disadvantages. This article deals with wire busbars.

Photo of the existing wire busbars is presented in Fig. 1.

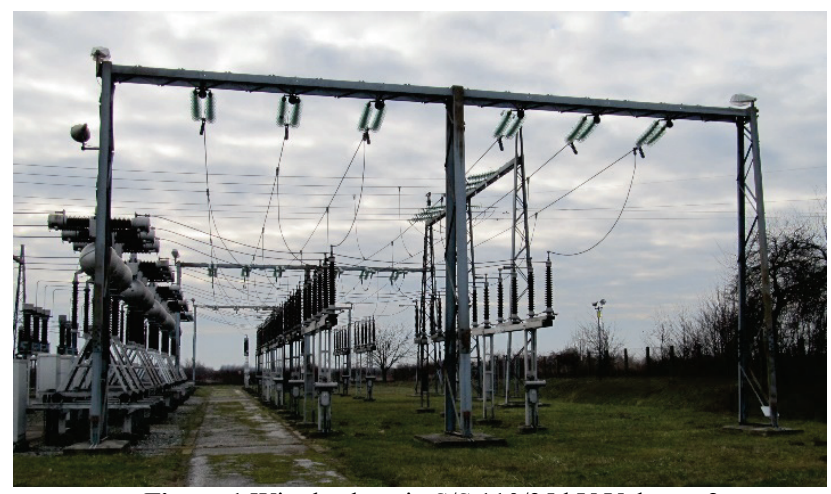

Figure 1 Wire busbars in S/S 110/35 kV Valpovo 2

The wire busbars consist of: wire conductors, insulator strings, spacers (for wire bundles), connectors (for incoming and outgoing bays), portals and foundations.

Aluminium wire conductors, steel reinforced aluminium wire conductors (ACSR) and aluminium alloy wire conductors (AAC) are usually used for wire (flexible) conductors. Wire conductor cross-section ranges $400 \div 800$ $\mathrm{mm}^{2}$. The span length is usually $10 \div 60 \mathrm{~m}$. For high nominal currents bundled wire conductors are used. They are composed of two wire conductors placed within the distance between bundled conductors, ranging $0.200 \div 0.400 \mathrm{~m}$. Wire conductors at the required spacing hold rigid spacers. The distance between rigid spacers ranges $2 \div 30 \mathrm{~m}$. Wire conductors are usually strained with an initial static stress in the order of $5 \div 20 \mathrm{~N} / \mathrm{mm}^{2}$. This is less than $10 \%$ of the nominal rupture conductor strength. The total sag (the sum of the wire conductor sag and the insulator string sag) under initial static stress equals about $3 \%$ of the span length. The sag is about $30 \%$ greater at the maximum permissible conductor temperature (for example $\left.80^{\circ} \mathrm{C}\right)$.
Strained wire conductors are connected to the steel supporting structures by insulator strings. The insulator string consists of cap and pin porcelain or glass insulator elements. For safety reason, insulator strings for wire busbars are almost allways doubled (as in Fig. 1).

Steel supporting structures are typically portals, usually made of latticed or solid welded steel and erected on concrete foundations. In this paper 3D truss type latticed steel structures are used. Structure elements are isoscele Lbeam elements. They are divided to two kinds - chord and lacing.

The increase in static stress of wire conductors increases the force on connecting points and also the cost of steel structures and foundations. Wire conductors phase spacing increasing will also cause changes in cost of steel structures because of steel width, but steel structure elements can be lighter because short-circuit force between phase conductors is inversely proportional to square phase spacing.

Because of the complex interrelationships between the busbars parameters, a method based on the application of GAs is used. The paper presents an original GA approach and presents results derived from several test cases.

The goal of this investigation is to design the cheapest wire busbars including costs of wire conductors, insulators, spacers, connectors, portals, foundations and terrain, but satisfying all electrical, mechanical and civil requirements and conditions on construction site.

To the author's knowledge, there are no papers from other authors dealing with the optimization of wire busbars. The paper is a continuation research of already published papers by the same author [3-6] and follows the concept of presenting 3D truss latticed portals with L-beam elements. The basis for the development of the described GA method are general papers [7, 8, 9], papers about usage of GA in electrical application [10-12] and papers in the field of optimization of steel structures [13, 14]. The program GAUSAB3D is developed in MATLAB, using Genetic Algorithm and Direct Search Toolbox.

Difference from past published papers is reduction of genetic variables by excluding dependent variables, including necessary connectors with belonging wire conductors for incoming and outgoing bays and cost for occupied terrain. 


\section{WIRE BUSBAR DESIGN}

The mechanical effects of short-circuit currents on wire busbars are well documented $[1,2]$. The short-circuit currents passing through phase wire conductors make the phase wire conductors swing with lower phase clearances $\left(a_{\mathrm{min}}\right)$ and higher tension forces (tensile force, drop force and bundle contraction force). The solutions to this problem are a higher static tension force, a higher conductor unit mass or a higher phase distance. All variants have influence on overall wire busbars cost mostly because of steel supporting structures, foundation and terain cost.

a)

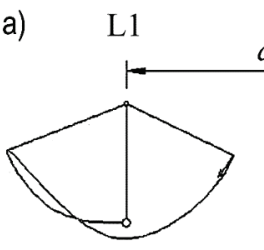

$\mathrm{L} 2$

L3

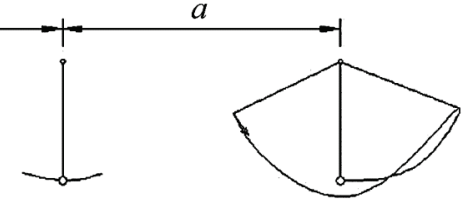

b) L1

L2

L3

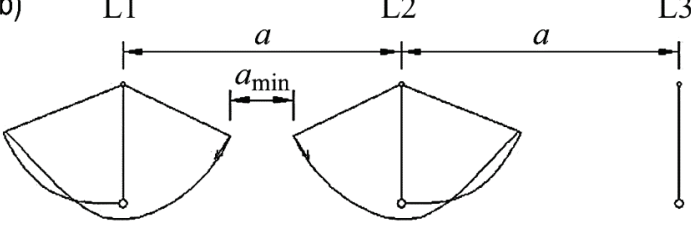

Figure 2 Phase conductor swing and clearance $a_{\min }$ [1]: a) three phase shortcircuit, b) two phase short-circuit.

The wire busbar design must satisfy all criteria with the lowest overall price. The wire busbar design criteria are:

- continuous current,

- $\quad$ short-circuit current,

- electrical surface field strength,

- wire conductor stress,

- insulator string force,

- deflection of steel structure nodes (less than $1 / 250$ of structure height),

- $\quad$ compressed steel L-type beam elements buckling,

- tensioned steel L-type beam elements stress,

- foundation soil pressure,

- $\quad$ steel structure overturning,

- $\quad$ wire conductor side swing.

The design goal is to optimize the cost of all components of the wire busbar system (C) (wire conductors, insulator strings, spacers, connectors, portals, foundations and terrain) that meet all technical requirements (electrical, mechanical and civil engineering).

$$
\begin{aligned}
& C=C_{1}+C_{2}+C_{3}+C_{4}+C_{5}+C_{6}+C_{7} \\
& C_{1}=3 n_{\text {conductor }} \times l_{\text {conductor }} \times c_{\text {conductor }} \times f_{\text {work }} \\
& C_{2}=6 c_{\text {insulator }} \times f_{\text {work }} \\
& C_{3}=3 n_{\text {spacer }} \times c_{\text {spacer }} \times f_{\text {work }} \\
& C_{4}=3 n_{\text {bay }} \times c_{\text {connector }} \times f_{\text {work }} \\
& C_{5}=2 m_{\text {portal }} \times c_{\text {steel }} \times f_{\text {work }} \\
& C_{6}=4 c_{\text {foundation }} \\
& C_{7}=4 a \times l_{\text {span }} \times c_{\text {terrain }}
\end{aligned}
$$

Wire busbar system price consists of the following costs: wire conductors cost $\left(C_{1}\right)$, insulator strings cost $\left(C_{2}\right)$, spacers cost $\left(C_{3}\right)$, connectors cost $\left(C_{4}\right)$, portal (steel structure) cost (according to portal mass) $\left(C_{5}\right)$, concrete foundations cost (according to foundation volume) $\left(C_{6}\right)$ and terrain cost (according to area between foundations) $\left(C_{7}\right)$.

In the first five costs cost of installation works (factor $f_{\text {work }}$ ) is included. Mark $c$ denotes unit prices.

Input data for the optimization process is wire busbar components database, data depending on the particular case and group of optimization parameters.

The results of the optimization process are discrete (integer) and continuous (real) values.

Discrete values are wire conductor type, number of wire conductors, insulator string type, spacers type, number of spacers, bundle distance, connectors for incoming and outgoing bays, chord L-type beam, lace Ltype beam and foundation type. In program GAUSAB3D these values are generated as real but they are rounded (up and down) to the integer value.

Continuous values are maximum static conductor horizontal stress and phase distance (with $0,1 \mathrm{~m}$ step).

Calculation of short-circuit effects on wire busbars (forces at attachment points and conductors side swing) are calculated according to the method described in international standards $[1,2]$. Steel structures and foundations must withstand short-circuit forces. Distance between swing-out conductors must be greater or equal to allowed clearance that depends on wire busbar nominal voltage.

Calculations of steel structure are based on known relations between vector of external forces $\{\boldsymbol{F}\}$, stiffness matrix $[\boldsymbol{K}]$ and vector of node shift $\{\boldsymbol{Q}\}$.

$$
\{\boldsymbol{Q}\}=[\boldsymbol{K}]^{-1}\{\boldsymbol{F}\}
$$

Calculations of stress in steel structure elements are done by Eq. (10) with Young modulus $(E)$, length $(L)$ and matrix of relation between local $\{\boldsymbol{q}\}$ and global $\{\boldsymbol{Q}\}$ node shift $[T]$.

$$
\begin{aligned}
& \sigma=\frac{E}{L}\left[\begin{array}{ll}
-1 & 1
\end{array}\right][T]\{\boldsymbol{Q}\} \\
& \{\boldsymbol{q}\}=[T]\{\boldsymbol{Q}\}
\end{aligned}
$$

The results are node shift, internal forces in steel structure elements, forces on foundations and moments on foundations. Limitations of steel structure are stated earlier. Stress in tensioned elements must be less than allowable values for steel and stress in compressed elements multiplied by factor for buckling must be less than allowable values for steel.

Checking of foundation overturn is done by comparison of moments on foundation by vertical and longitudinal forces.

$\frac{M_{\text {vert }}}{M_{\text {long }}} \geq 1,5$ 
Calculation of foundation soil pressure is done by dividing sum of all vertical forces - weight of steel structure $W_{\mathrm{ss}}$, concrete foundation $W_{\mathrm{cf}}$ and soil over foundation $W_{\text {sof }}$ by foundation foot area $A_{x} A_{y}$. Obtained value must be multiplied by factor depending on moments of longitudinal forces $f_{\mathrm{mlf}}$. Calculated foundation soil pressure must be lower than allowed soil pressure.

$$
\sigma_{\text {soil }}=f_{\mathrm{mlf}} \frac{W_{\mathrm{ss}}+W_{\mathrm{cf}}+W_{\mathrm{sof}}}{A_{x} \times A_{y}} \leq \sigma_{\text {soil, allow }}
$$

\section{OPTIMIZATION BY GENETIC ALGORITHMS}

Because of the mixed type of variables (integer and real) for the process of wire busbars optimization the method of GAs is selected. A Genetic Algorithm and Direct Search Toolbox for use with MATLAB aim to make the GAs accessible to the design engineer within the framework of a calculation/simulation package. This allows the retention of existing modelling and simulation tools for building objective functions and allows the user to make direct comparisons between genetic methods and traditional procedures.

The procedure method of GAs:

1. Generation of an initial population.

2. Calculation of the initial population fitness.

3. Selection of the most appropriate individuals.

4. Creation of a new population by genetic crossover procedures.

5. Creation of a new population by genetic mutation process.

6. Calculation of the current population fitness.

7. Selection of the most appropriate individuals.

8. Checking the condition of convergence (maximum number of generations reached, stall fitness, operating time maximum reached, ...). If the answer is YES then jump to 9 , if NO then jump to 4 .

9. Save Solution.

The wire busbar system is defined by the values of design variables. The design variables, values and type are shown in Tab. 1.

Table 1 Design variables

\begin{tabular}{|c|c|c|}
\hline Design variable & Values & Type \\
\hline Conductor type & database index & integer \\
\hline Bundle distance & database index & integer \\
\hline Spacer number & from interval & integer \\
\hline Conductor stress & from interval & real \\
\hline Phase distance & from interval & real \\
\hline L-beam - chord & database index & integer \\
\hline L-beam - lacing & database index & integer \\
\hline Foundation & database index & integer \\
\hline
\end{tabular}

Other components of wire busbar are uniquely determined by above genetic variables.

Insulator string is uniquely determined by conductor and bundle distance.

Rigid spacer is uniquely determined by conductor and bundle distance.

Spacer with branch is uniquely determined by main conductor, bundle distance and branch conductor

$\mathrm{T}$-connector is uniquely determined by main conductor and branch conductor.
The tableau for the wire busbar design is shown in Tab. 2.

Table 2 Tableau for the wire busbar design

\begin{tabular}{|l|l|}
\hline Objective & $\begin{array}{l}\text { Find the globally optimum combination of eight } \\
\text { wire busbar parameters }\end{array}$ \\
\hline $\begin{array}{l}\text { Representation } \\
\text { scheme }\end{array}$ & $\begin{array}{l}\text { Structure: fixed length } \\
\text { Alphabet size: real values (Integer values are } \\
\text { obtained by rounding up or down) } \\
\text { String length: } 8\end{array}$ \\
\hline Fitness cases & Only one \\
\hline Fitness & $\begin{array}{l}\text { Wire busbar price. Penalties for criteria violation. } \\
\text { The lowest value is the best. }\end{array}$ \\
\hline Parameters & $\begin{array}{l}\text { Population size } \\
\text { Maximum number of generations }\end{array}$ \\
\hline $\begin{array}{l}\text { Termination } \\
\text { criteria }\end{array}$ & $\begin{array}{l}\text { Maximum number of generations or stall } \\
\text { generation or maximum time. }\end{array}$ \\
\hline Result designation & The best so far individual in the population. \\
\hline
\end{tabular}

The structure of program GAUSAB3D is shown in Fig. 3.

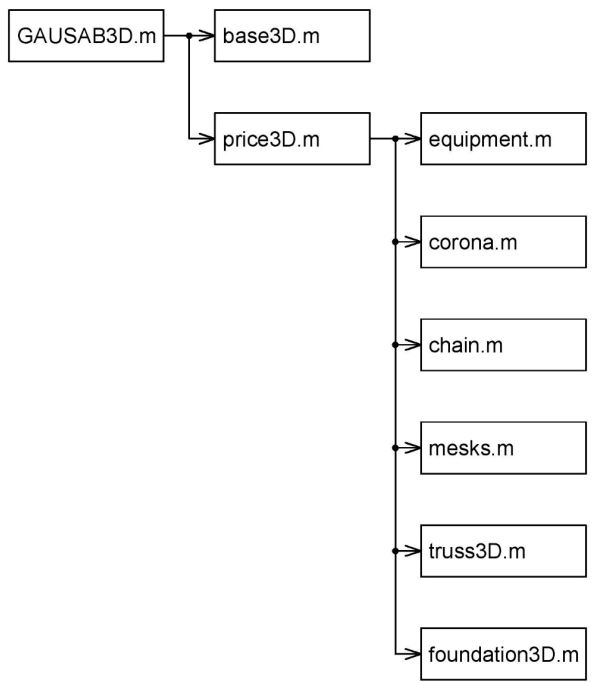

Figure 3 Program GAUSAB3D structure

GAUSAB3D.m is own developed main program. It calls data base, reads input data, calls MATLAB GA procedure and prints results. Subroutine base3D.m reads data from data base. Subroutine price3D.m is fitness function and it calculates the cost for individual solution. Subroutine equipment.m determines dependent components (insulator string, spacer, spacer with branch and T-connector). Subroutine corona.m calculates electric surface field strength (corona effects). Subroutine chain calculates static forces at attachment points, horizontal stress and sag of wire busbars. Subroutine mesks.m calculates forces and conductor side swing under passing short-circuit current. Subroutine truss3D.m calculates deflection of steel structure, forces in L-type elements, forces and moments on foundations and buckling of L-type elements. Subroutine foundation3D.m calculates pressure on soil and checks overturn of steel structure and foundation.

\section{TEST EXAMPLE}

\subsection{Basic Data}

Main wire busbar data are span length $36 \mathrm{~m}$, portal height $8 \mathrm{~m}$, continuous current $1200 \mathrm{~A}$, short-circuit current $16 \mathrm{kA}$, short-circuit duration $0,5 \mathrm{~s}$, factor kappa 
1,70 , factor $\mathrm{m} 0,05$, factor $\mathrm{n} 0,95$, nominal voltage $110 \mathrm{kV}$, minimum clearance during short-circuit $450 \mathrm{~mm}$, number of incoming/outgoing bays 4, incoming/outgoing wire conductor AAC 400, length of incoming/outgoing wire conductor $4 \mathrm{~m}$, lowest wire conductor temperature $-20^{\circ} \mathrm{C}$ and highest wire conductor temperature $60^{\circ} \mathrm{C}$.

Conductor static stress interval equals $2,5 \div 20 \mathrm{~N} / \mathrm{mm}^{2}$, phase conductor centreline spacing interval equals $2,5 \div$ $5,0 \mathrm{~m}$ (with $0,1 \mathrm{~m}$ steps) and number of spacers are $0 \div 10$.

Main steel structure data are Fe360 elasticity module $210 \mathrm{kN} / \mathrm{mm}^{2}$, Fe 360 permissible tensile stress $235 \mathrm{~N} / \mathrm{mm}^{2}$, dynamic force safety factor 1,3 and static force safety factor 1,5 .

Concrete foundation data are concrete density 2400 $\mathrm{kg} / \mathrm{m}^{3}$, soil density $1800 \mathrm{~kg} / \mathrm{m}^{3}$ and allowable soil bearing pressure $150000 \mathrm{~N} / \mathrm{m}^{2}$.

Main prices are steel price 2,67 EUR/kg, concrete price with steel armature $240,00 \mathrm{EUR} / \mathrm{m}^{3}$ and terrain price $20,00 \mathrm{EUR} / \mathrm{m}^{2}$ and cost of wire busbar installation $20 \%$ $\left(f_{\text {work }}\right)$.

Penalizing a fitness function for violating the criteria is equal to 100000,00 euros.

The wire busbars components database parameters are number of wire conductors 3 , number of conductor phase distances 5, number of insulator strings 5, number of rigid spacers 12, number of rigid spacers with branch 12 , number of T-type connectors 3, number of steel isosceles L type beams 7 and number of foundations 6 .

Parameters of GA procedure are population size 200, maximum generations 50, stall generation limit 10 , crossover fraction 0,5 and elite count 20.

Main portal dimensions are column width $0,60 \mathrm{~m}$, column bottom length $1,60 \mathrm{~m}$, column height $8,00 \mathrm{~m}$, column top length $0,60 \mathrm{~m}$ and horizontal beam height 0,50 $\mathrm{m}$.

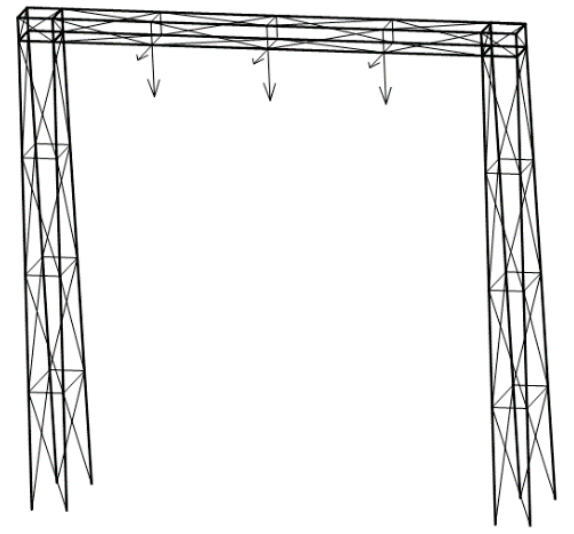

Figure 4 Lattice steel portal with chord (bold) and lacing L type elements

Distance between portal columns axis equals four-way distance between phase wire conductors. The distance between phase wire conductors is optimization variable so the distance between portal columns is also variable. Total number of nodes equals 60 and total number of elements equals 166. Eight nodes are fixed on foundation. On two left connection nodes are connected wire conductors using insulator strings with horizontal tension short-circuit force (static force with maximum value between three shortcircuit forces - tensile force, drop force and bundle contraction force). On the third connection node is connected wire conductor with static tension force. On all three nodes are acting vertical force due to the mass of insulator strings, wire conductors, spacers, connectors and incoming/outgoing wire conductors. The selected foundation type (spread footing) is shown in Fig. 5 and with data in Tab. 3.

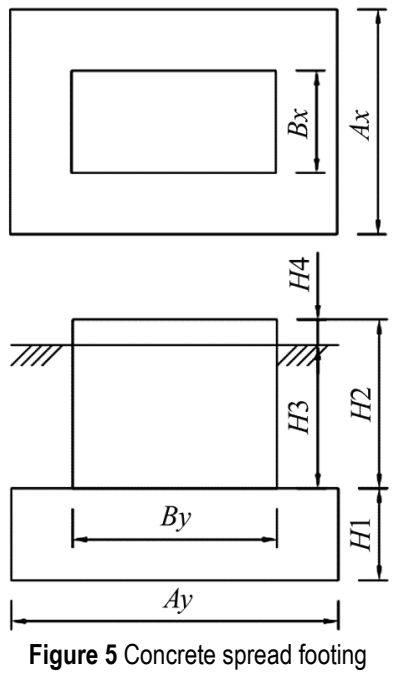

Table 3 Foundation data

\begin{tabular}{|c|c|c|c|c|c|c|}
\hline Variant & T1 & T2 & T3 & T4 & T5 & T6 \\
\hline$A x(\mathrm{~m})$ & 1,80 & 2,00 & 2,20 & 2,40 & 2,60 & 2,80 \\
\hline$A y(\mathrm{~m})$ & 2,80 & 3,00 & 3,20 & 3,40 & 3,60 & 3,80 \\
\hline$B x(\mathrm{~m})$ & 1,00 & 1,00 & 1,00 & 1,00 & 1,00 & 1,00 \\
\hline$B y(\mathrm{~m})$ & 2,00 & 2,00 & 2,00 & 2,00 & 2,00 & 2,00 \\
\hline$H 1(\mathrm{~m})$ & 0,90 & 0,90 & 0,90 & 0,90 & 0,90 & 0,90 \\
\hline$H 2(\mathrm{~m})$ & 1,45 & 1,55 & 1,65 & 1,75 & 1,85 & 1,95 \\
\hline$H 3(\mathrm{~m})$ & 1,20 & 1,30 & 1,40 & 1,50 & 1,60 & 1,70 \\
\hline$H 4(\mathrm{~m})$ & 0,25 & 0,25 & 0,25 & 0,25 & 0,25 & 0,25 \\
\hline
\end{tabular}
$4 \div 10$.

Other input data from data base are presented in Tabs.

Table 4 Wire conductor data

\begin{tabular}{|l|c|c|c|}
\hline Variant & 1 & 2 & 3 \\
\hline Type & AAC400 & AAC625 & AAC800 \\
\hline Area $\left(\mathrm{mm}^{2}\right)$ & 400,14 & 626,2 & 802,09 \\
\hline Diameter $(\mathrm{mm})$ & 26,00 & 32,60 & 36,90 \\
\hline Nominal current $(\mathrm{A})$ & 855 & 1140 & 1340 \\
\hline Short-circuit current, 1 s $(\mathrm{kA})$ & 60,86 & 95,25 & 118,39 \\
\hline Unit mass $(\mathrm{kg} / \mathrm{m})$ & 1,104 & 1,732 & 2,218 \\
\hline Number of wires & 61 & 91 & 91 \\
\hline$E\left(\mathrm{~N} / \mathrm{mm}^{2}\right)$ & 55000 & 55000 & 55000 \\
\hline$\beta\left(1 /{ }^{\circ} \mathrm{C}\right)$ & 0,000023 & 0,000023 & 0,000023 \\
\hline$\rho\left(\mathrm{kg} / \mathrm{m}^{3}\right)$ & 2700 & 2700 & 2700 \\
\hline$\sigma_{\max }\left(\mathrm{N} / \mathrm{mm}^{2}\right)$ & 83,60 & 83,60 & 83,60 \\
\hline$C_{\text {th }}\left(\mathrm{m}^{4} /\left(\mathrm{A}^{2} \cdot \mathrm{s}\right)\right)$ & $0,27 \times 10^{-18}$ & $0,27 \times 10^{-18}$ & $0,27 \times 10^{-18}$ \\
\hline Unit $\mathrm{price}(\mathrm{EUR} / \mathrm{m})$ & 3,87 & 6,00 & 7,73 \\
\hline
\end{tabular}

Table 5 Available bundle distances

\begin{tabular}{|l|c|c|c|c|c|}
\hline Variant & 1 & 2 & 3 & 4 & 5 \\
\hline Bundle distance (m) & 0 & 0,200 & 0,240 & 0,330 & 0,400 \\
\hline
\end{tabular}

Table 6 T-connector data
\begin{tabular}{|l|c|c|c|}
\hline Variant & 1 & 2 & 3 \\
\hline Type & $\mathrm{A} 6.30 .30$ & $\mathrm{~A} 6.35 .30$ & $\mathrm{~A} 6.40 .30$ \\
\hline Main conductor diameter $(\mathrm{mm})$ & $20-30$ & $30-35$ & $35-40$ \\
\hline Branch conductor diameter $(\mathrm{mm})$ & $20 \div 30$ & $20 \div 30$ & $20 \div 30$ \\
\hline Mass $(\mathrm{kg})$ & 2,65 & 2,80 & 2,85 \\
\hline Price (EUR) & 107,00 & 115,00 & 117,00 \\
\hline
\end{tabular}


Table 7 Insulator string data

\begin{tabular}{|l|c|c|c|c|}
\hline Variant & 1 & 2 & 3 & 4 \\
\hline Type & $2 Z 1$ & $2 Z 2-200$ & $2 Z 2-240$ & $2 Z 2-330$ \\
\hline Number of units & $2 \times 8$ & $2 \times 8$ & $2 \times 8$ & $2 \times 2-400$ \\
\hline Insulator unit & U160BS & U160BS & U160BS & U160BS \\
\hline Length (m) & 1,60 & 2,07 & 2,07 & 2,07 \\
\hline Mass (kg) & 112,60 & 132,60 & 132,60 & 2,07 \\
\hline Number of conductors & 1 & 2 & 2,07 & 2 \\
\hline Bundle distance (m) & - & 0,200 & 0,240 & 0,330 \\
\hline Price (EUR) & 693,00 & 747,00 & 760,00 & 773,00 \\
\hline
\end{tabular}

Table 8 Rigid spacer data

\begin{tabular}{|l|c|c|c|c|c|}
\hline Variant & 1 & 2 & 3 & 4 & 5 \\
\hline Type & $\mathrm{A} 6.30 .00 .200$ & $\mathrm{~A} 6.30 .00 .240$ & $\mathrm{~A} 6.30 .00 .330$ & $\mathrm{~A} 6.30 .00 .400$ & $\mathrm{~A} 6.35 .00 .200$ \\
\hline Bundle distance $(\mathrm{mm})$ & 200 & 240 & 330 & 400 & 200 \\
\hline Conductor diameter $(\mathrm{mm})$ & $20 \div 30$ & $20 \div 30$ & $20 \div 30$ & $20 \div 30$ & $30 \div 35$ \\
\hline Mass (kg) & 1,56 & 1,64 & 1,82 & 1,96 & 1,76 \\
\hline Price (EUR) & 64,00 & 67,50 & 74,50 & 80,50 & 72,00 \\
\hline
\end{tabular}

\begin{tabular}{|c|c|c|c|c|c|c|}
\hline 6 & 7 & 8 & 9 & 10 & 11 & 12 \\
\hline $\mathrm{A} 6.35 .00 .240$ & $\mathrm{~A} 6.35 .00 .330$ & $\mathrm{~A} 6.35 .00 .400$ & $\mathrm{~A} 6.40 .00 .200$ & $\mathrm{~A} 6.40 .00 .240$ & $\mathrm{~A} 6.40 .00 .330$ & $\mathrm{~A} 6.40 .00 .400$ \\
\hline 240 & 330 & 400 & 200 & 240 & 330 & 400 \\
\hline $30-35$ & $30 \div 35$ & $30 \div 35$ & $35 \div 40$ & $35 \div 40$ & $35 \div 40$ & $35 \div 40$ \\
\hline 1,84 & 2,05 & 2,20 & 1,96 & 2,04 & 2,25 & 2,40 \\
\hline 75,50 & 84,00 & 90,00 & 80,50 & 84,00 & 92,00 & 99,00 \\
\hline
\end{tabular}

Table 9 Spacer with branch data

\begin{tabular}{|c|c|c|c|c|c|c|}
\hline \multirow{2}{*}{\multicolumn{2}{|c|}{ Variant }} & & & & & \\
\hline & & 1 & 2 & 3 & 4 & 5 \\
\hline \multicolumn{2}{|l|}{ Type } & A6.30.30.200 & A6.30.30.240 & A6.30.30.330 & A6.30.30.400 & A6.35.30.200 \\
\hline \multicolumn{2}{|c|}{ Bundle distance $(\mathrm{mm})$} & 200 & 240 & 330 & 400 & 200 \\
\hline \multicolumn{2}{|c|}{ Main conductor diameter (mm) } & $20 \div 30$ & $20 \div 30$ & $20 \div 30$ & $20 \div 30$ & $30 \div 35$ \\
\hline \multicolumn{2}{|c|}{ Branch conductor diameter $(\mathrm{mm})$} & $20 \div 30$ & $20 \div 30$ & $20 \div 30$ & $20 \div 30$ & $20 \div 30$ \\
\hline \multicolumn{2}{|c|}{ Mass (kg) } & 2,87 & 2,95 & 3,10 & 3,25 & 3,05 \\
\hline \multicolumn{2}{|l|}{ Price (EUR) } & 118,00 & 121,50 & 127,50 & 133,50 & 125,50 \\
\hline 6 & 7 & 8 & 9 & 10 & 11 & 12 \\
\hline A6.35.30.240 & A6.35.30.330 & A6.35.30.400 & A6.40.30.200 & A6.40.30.240 & A6.40.30.330 & A6.40.30.400 \\
\hline 240 & 330 & 400 & 200 & 240 & 330 & 400 \\
\hline $30 \div 35$ & $30 \div 35$ & $30 \div 35$ & $35 \div 40$ & $35 \div 40$ & $35 \div 40$ & $35 \div 40$ \\
\hline $20 \div 30$ & $20 \div 30$ & $20 \div 30$ & $20 \div 30$ & $20 \div 30$ & $20 \div 30$ & $20 \div 30$ \\
\hline 3,15 & 3,40 & 3,55 & 3,23 & 3,35 & 3,70 & 3,85 \\
\hline 129,50 & 139,50 & 145,50 & 133,50 & 137,50 & 152,00 & 158,00 \\
\hline
\end{tabular}

Table 10 Isosceles steel $\mathrm{L}$ beam elements data

\begin{tabular}{|c|c|c|c|c|c|c|c|}
\hline Variant & 1 & 2 & 3 & 4 & 5 & 6 & 7 \\
\hline Type & $\mathrm{L} 60 \times 8$ & $\mathrm{~L} 70 \times 9$ & $\mathrm{~L} 80 \times 10$ & L90 $\times 11$ & $\mathrm{~L} 100 \times 12$ & $\mathrm{~L} 110 \times 12$ & $\mathrm{~L} 120 \times 13$ \\
\hline$a(\mathrm{~mm})$ & 60 & 70 & 80 & 90 & 100 & 110 & 120 \\
\hline$s(\mathrm{~mm})$ & 8 & 9 & 10 & 11 & 12 & 12 & 13 \\
\hline Unit mass $(\mathrm{kg} / \mathrm{m})$ & 7,09 & 9,34 & 11,9 & 14,7 & 17,8 & 19,7 & 23,3 \\
\hline Moment of inertia $\left(\mathrm{cm}^{4}\right)$ & 29,1 & 52,6 & 87,5 & 138 & 207 & 280 & 394 \\
\hline
\end{tabular}

Table 11 Results of GA runs

\begin{tabular}{|c|c|c|c|c|c|c|}
\hline Case & 1 & 2 & 3 & 4 & 5 & 6 \\
\hline Nominal current (A) & 1200 & 2000 & 1200 & 2000 & 1200 & 2000 \\
\hline Short-circuit current (kA) & 16 & 16 & 25 & 25 & 25 & 25 \\
\hline Short-circuit duration (s) & 0,5 & 0,5 & 0,5 & 0,5 & 1 & 1 \\
\hline Number of generations & 40 & 50 & 41 & 50 & 50 & 25 \\
\hline Termination & Stall & $\begin{array}{l}\text { Maximum } \\
\text { generation }\end{array}$ & Stall & $\begin{array}{l}\text { Maximum } \\
\text { generation }\end{array}$ & $\begin{array}{l}\text { Maximum } \\
\text { generation }\end{array}$ & Stall \\
\hline Conductor & AAC 800 & AAC625 & AAC 800 & AAC625 & AAC800 & AAC625 \\
\hline Number of conductors & 1 & 2 & 1 & 2 & 1 & 2 \\
\hline Insulator string & $2 \mathrm{Z1}$ & $2 \mathrm{Z2}-200$ & $2 \mathrm{Z1}$ & $2 \mathrm{Z2}-200$ & $2 \mathrm{Z1}$ & $2 Z 2-200$ \\
\hline Bundle distance $(\mathrm{m})$ & 0,000 & 0,200 & 0,000 & 0,200 & 0,000 & 0,200 \\
\hline L-beam (chord) & LB $90 \times 11$ & LB100 $\times 12$ & LB100 $\times 12$ & LB100 $\times 12$ & LB100 $\times 12$ & LB120 $\times 13$ \\
\hline L-beam (lacing) & LB $80 \times 10$ & LB $80 \times 10$ & LB $80 \times 10$ & LB90 $\times 11$ & LB $80 \times 10$ & LB $80 \times 10$ \\
\hline Foundation & $\mathrm{T} 2$ & $\mathrm{~T} 3$ & $\mathrm{~T} 4$ & T5 & $\mathrm{T} 4$ & T5 \\
\hline Conductor stress $\left(\mathrm{N} / \mathrm{m}^{2}\right)$ & 5,99 & 5,77 & 12,26 & 8,55 & 12,32 & 6,97 \\
\hline Phase spacing $(\mathrm{m})$ & 2,70 & 2,60 & 2,50 & 2,50 & 2,60 & 2,50 \\
\hline Number of connectors & 4 & 4 & 4 & 4 & 4 & 4 \\
\hline Type of connectors & A1.40.30 & A6.35.30.200 & A1.40.30 & A6.35.30.200 & A1.40.30 & A6.35.30.200 \\
\hline Number of spacers & 0 & 1 & 0 & 0 & 0 & 1 \\
\hline Type of spacers & - & A6.35.00.200 & - & - & - & A6.35.00.200 \\
\hline Price $\left(10^{3} \times\right.$ EUR $)$ & 47,22 & 51,70 & 50,64 & 55,75 & 51,23 & 57,55 \\
\hline
\end{tabular}




\subsection{Results}

The results of 6 runs of programme GAUSAB3D are presented in Tab. 11. Case 1 is performed with data from chapter 4.1. Cases 2, 3, 4, 5 and 6 are performed with change in nominal current, short-circuit current and shortcircuit duration.

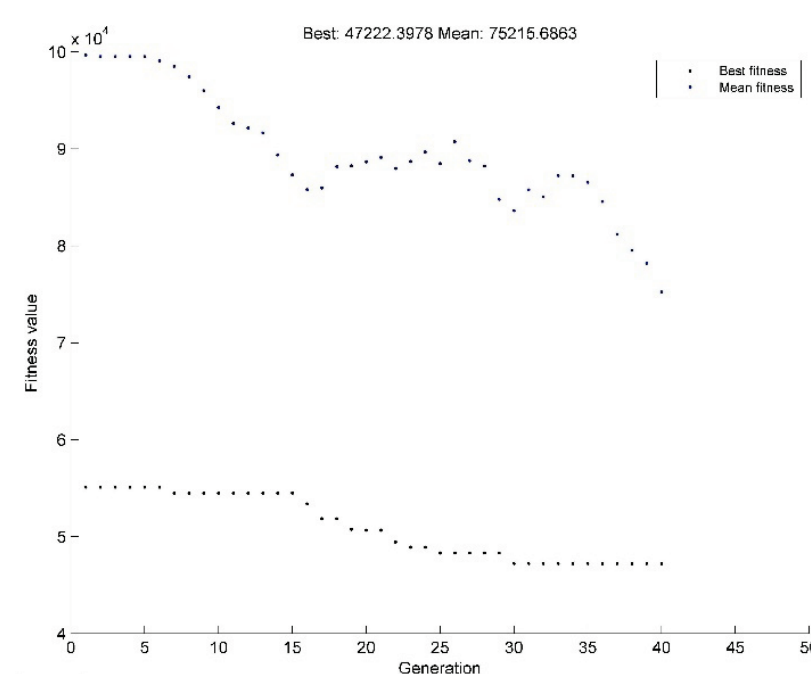

Figure 6 Best and Mean Price vs. Generations - Case 1

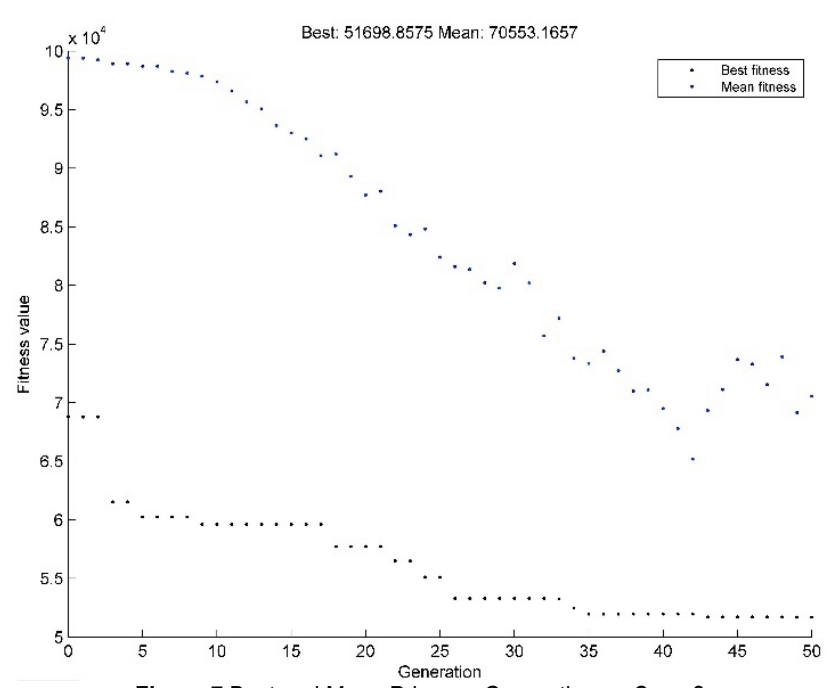

Figure 7 Best and Mean Price vs. Generations - Case 2

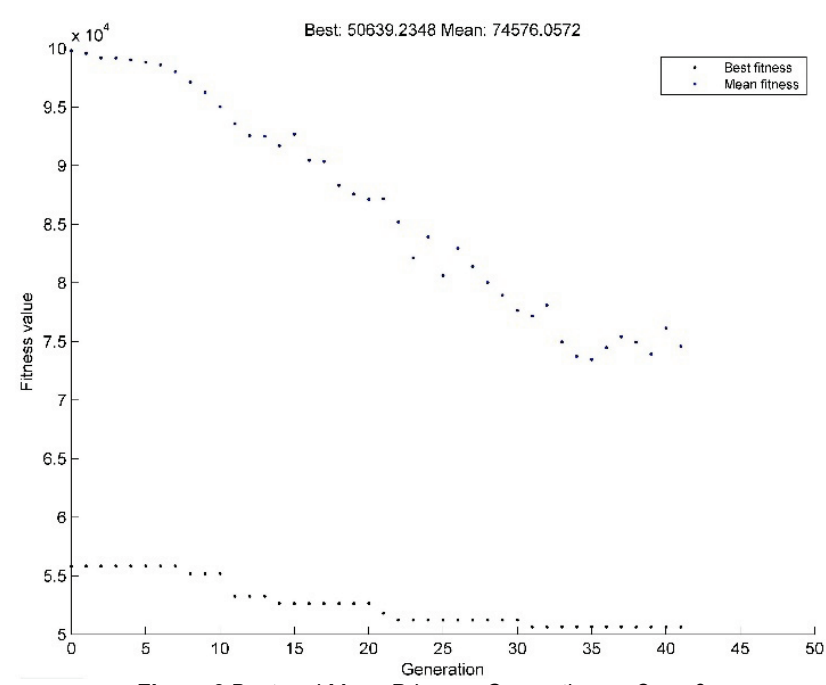

Figure 8 Best and Mean Price vs. Generations - Case 3
The flows of the optimization procedures runs are shown in Figs. $6 \div 11$.

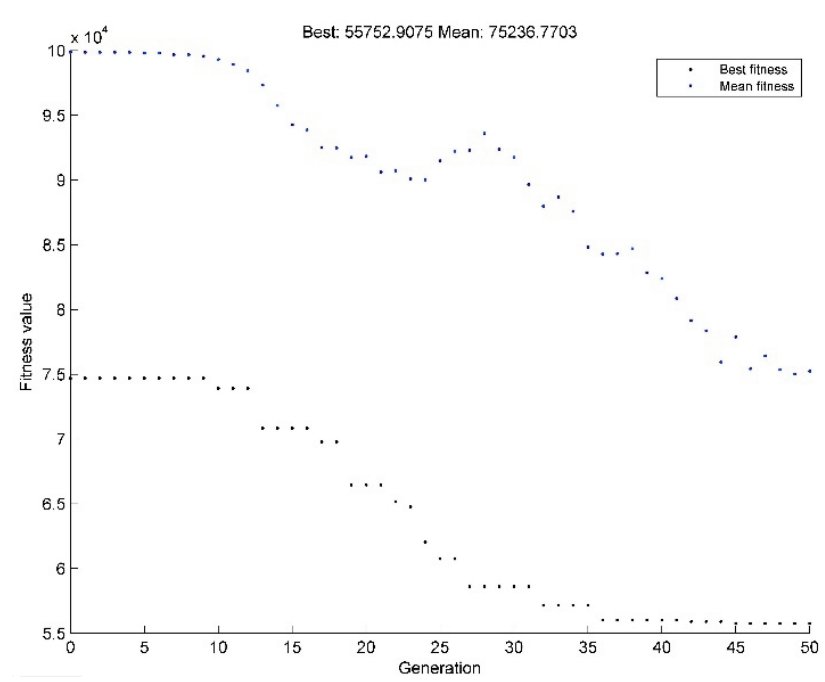

Figure 9 Best and Mean Price vs. Generations - Case 4

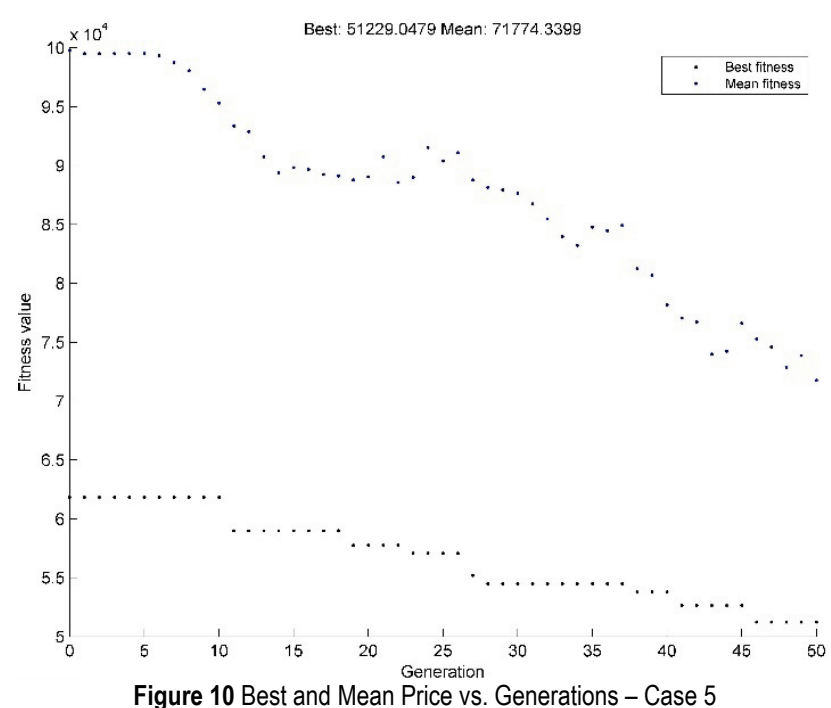

Figure 10 Best and Mean Price vs. Generations - Case 5

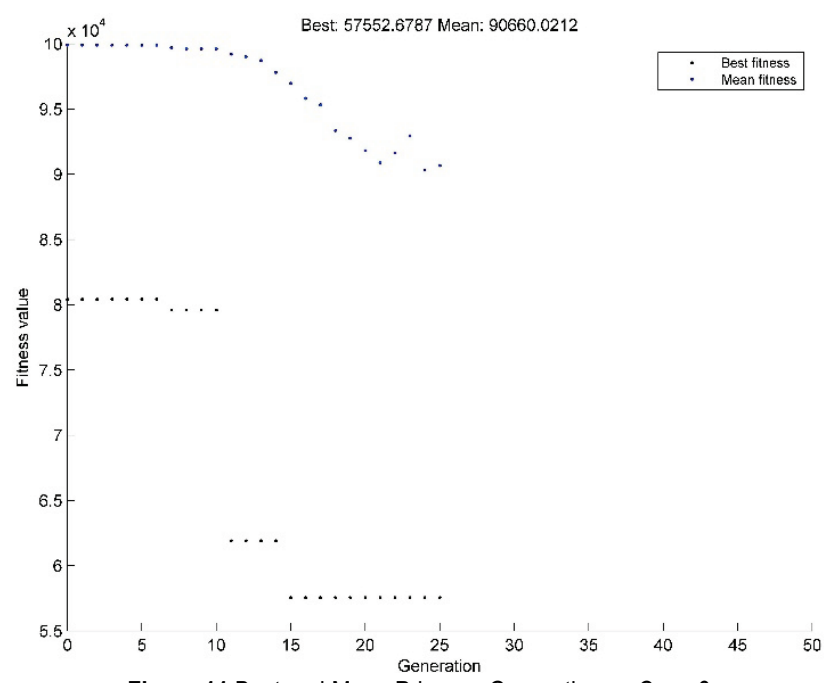

Figure 11 Best and Mean Price vs. Generations - Case 6

\subsection{Analyses}

Results from Tab. 11 show expected variation in prices for various combinations of nominal current, short-circuit current and short-circuit duration. 
Increase of nominal current gives increase of wire conductor cross-section and overall cost.

Increase of short-circuit current gives increase in dimension of L-type steel elements and foundations, which results in increasing of overall cost.

Increase of short-circuit duration gives increase in dimension of L-type steel elements, foundations and distance between phase conductors, which results in increasing of overall cost.

Because of the stochastic nature of genetic algorithms user must try several runs with identical input data to obtain global optimum instead of local optimum. Recommended number of runs with identical input data equals 5 .

\section{CONCLUSION}

The article describes the application of GA to the problem of designing the optimal wire busbar. Some of the design variables have discrete values and the others have continuous values. The reason for choice of GA method is the ability to calculate wire busbars and use GA within a MATLAB program with GA and Direct Search Toolbox. The fitness function (in our case is also objective function) is a sum of the wire busbars components prices. If the generated wire busbar does not meet the criteria set, then it is given high costs and thus eliminates the solution from the selection procedure.

Difference from past published papers is reduction of the number of genetic variables by excluding dependent variables, including necessary connectors with belonging wire conductors for incoming and outgoing bays and cost for occupied terrain.

Optimization of the busbar system by using developed program GAUSAB3D is demonstrated on test example. Figs. $6 \div 11$ present the gradual approaching to the optimal solution.

Large population size (200) gives already at the initial generation possible solution for wire busbar. The price of the initial solution is gradually reduced to the cost of the optimal solution. The biggest impact on the cost of wire busbar have the costs of steel structure $\left(C_{5}\right)$, foundation $\left(C_{6}\right)$ and terrain $\left(C_{7}\right)$

There is a lack of similar research due to the complexity of a program, the problem that includes electrical, mechanical and civil calculations.

The future development work can be done by improvement of the Genetic Algorithms efficiency and more complex steel structures. Genetic Algorithms efficiency can be improved by the choice of optimal GA parameters (population size, number of generations, selection procedure, crossover rate and mutation rate). The ultimate goal is to reduce the number of fitness evaluations (population size times number of generations) necessary to obtain the optimal solution.

\section{REFERENCES}

[1] The mechanical effects of short-circuit currents in open air substations (Rigid and Flexible Bus-Bars). CIGRE Study Committee 23 (Substations), Working Group 23-11 (Substations and Environment), ESCC Task Force (Effects of Short-Circuit Currents), Volume 1, An Updated Revision of CIGRE Brochure of 1987, April 1996.
[2] Short-circuit currents - Calculation of effects, Part 1. definitions and calculation methods. IEC 865-1, second edition, IEC, Geneve, 1993.

[3] Petranovic, D. (2006). Design of Substation Wire Busbars Using Genetic Algorithms. Proceedings of the $29^{\text {th }}$ MIPRO, Vol III, CTS \& CIS / Opatija, 211-215.

[4] Petranovic, D. (2012). Application of genetic algorithms in wire busbars design. Proceedings of the $35^{\text {th }}$ MIPRO, CIS / Opatija, 1239-1244.

[5] Petranovic, D. \& Marusic, A. (2014). Genetic Algorithm Approach to Optimum Wire Busbar design. Proceedings of the MOTSP / Bol, 1-8.

[6] Petranovic, D. \& Marusic, A. (2015).Application of genetic algorithms in wire busbars design with 3D Trust. Engineering Review, 35(3), 309-316.

[7] Koza, J. R. (1992). Genetic Programming: On the Programming of Computers by Means of Natural Selection, Cambridge, USA: The MIT Press.

[8] Švaco, M., Jerbić, B., \& Šekoranja, B. (2017). Task Planning Based on the Interpretation of Spatial Structures. Tehnicki vjesnik, 24(2), 427-434. https://doi.org/10.17559/TV-20160118150332

[9] Janeš, G., Perinić, M., \& Jurković, Z. (2017). Applying Improved Genetic Algorithm for Solving Job Shop Scheduling Problems. Tehnicki vjesnik, 24 (2), 1243-1247. https://doi.org/10.17559/TV-20150527133957

[10] Petranovic, D. (2012).Stadium Reflector Aiming Using Genetic Algorithms. Proceedings of the $35^{\text {th }}$ MIPRO, CIS / Opatija, 1251-1256.

[11] Petranovic, D. (2015). Football Stadium Floodlight Aiming by Using a Genetic Algorithm with Multi-step Approach. Polytechnic \& Design, 3(2), 135-143.

[12] Kostov, I., Spasov, V., \& Rangelova, V. (2009). Application of Genetic Algorithms for Determining the Parameters of Induction Motors. Tehnicki vjesnik, 16(2), 49-53.

[13] Turkkan, N. (2003).Discrete optimization of structures using a floating point genetic algorithm. Proceedings of the Annual Conference of the Canadian Society for Civil Engineering / Moncton, Nouveau-Brunswick, Canada, 1-8.

[14] Hultman, M. (2010). Weight optimization of steel structures by a genetic algorithm - Size, shape and topology optimization according to Eurocode. Rapport TVBK - 5176, Lund Institute of Technology, Lund, Sweden, 1-61.

Contact Information:

Davor PETRANOVIĆ, PhD, Senior Lecturer

Zagreb University of Applied Sciences, Konavoska 2, 10000 Zagreb, Croatia davor.petranovic@tvz.hr

Ante MARUŠıć, PhD, Full Professor

University of Zagreb,

Faculty of Electrical Engineering and Computing,

Unska 3, 10000 Zagreb, Croatia

ante.marusic@fer.hr

Juraj HAVELKA, PhD, Assistant Professor

University of Zagreb,

Faculty of Electrical Engineering and Computing

Unska 3, 10000 Zagreb, Croatia

juraj.havelka@fer.hr 